\title{
Correspondence
}

\section{On the current state of psychiatry in Northern Italy \\ DeAr Sirs}

In a letter in the British Journal of Psychiatry, Dr Thiels' comments on the 'rather obscure psychiatric scene in Northern Italy' and on the fact that the alleged benefits (see Mosher ${ }^{2}$ ) are poorly documented and 'not supported by direct scientific evidence, but mainly conviction.' An extensive report on the state of psychiatric practice in Italy following the passage of the 'Basaglia' act in May 1978 was presented by Mosher $^{2}$ with a generally favourable verdict. Jones and Poletti $i^{3}$ have reviewed several generally favourable reports in some British nursing and social work journals on the Italian experiment. Unfortunately these reports seem to have depended for their data mainly on the propaganda of Basaglia's organization, Psichiatria Democratica, rather than an in-depth examination of the situation in Italy as it really is, and not as seen through a mist of romantic and wishful thinking (see, for example, Johl').

I have recently spent two months visiting psychiatric centres in Northern Italy, including Trieste (where Dr Basaglia practised), Venice, Florence, Milan, and others, as well as the University of Innsbruck, which functions as the university town for the South Tyrol (part of Italy since 1919). I visited hospitals and clinics and spoke to practising psychiatrists, nurses and social workers. My contacts were helped by the fact that my wife comes from Trieste, and acted as interpreter for me. I have had an intimate knowledge of Trieste and its people for over thirty years.

My verdict, contrary to Dr Mosher's, is that the general effect of the 'Basaglia law' has been nothing less than disastrous, and represents a triumph of psychiatric naïvety, inflexible dogma, romanticism, and political bias over common sense.

The factors that led up to this débâcle are as follows. In the early 1960s, Basaglia attempted to apply the teachings of Maxwell Jones concerning the therapeutic community in an old rundown psychiatric hospital in Gorizia, near Trieste. After two years, Mosher says, Basaglia became 'disillusioned' by the failure of the Jones technique to 'motivate' these chronic patients to leave the hospital. Instead of concluding that many cases of chronic schizophrenia have as their basis an organic malfunction of the brain, as is generally accepted in most academic centres elsewhere, he made the bold hypothesis, unsupported by any evidence, that the cause of the problem was the institution itself-'its authoritarianism, hierarchy, inflexibility, and medicalization of "social" problems' $\left(M_{0 s h e r}^{2}\right.$-and so he set to work to dismantle the hospital, attempting to replace it entirely with community-based residential programmes. Over a five-year period (1963-1968) the population of the hospital was reduced by more than half.

In Trieste, where Basaglia went in 1972, the public psychiatric services are now delivered by small mental health centres (Centri Psico-Sociali) backed up by a ten-bedded ward in the local general hospital, and the old mental hospital now housing ospiti (guests). For the past six years no new patients have been admitted to the state psychiatric hospitals in Italy, which consequently have small populations. For example, the vast hospital built by the Hapsburgs in Venice that I visited has now only 150 patients, called ospiti. Other than that the centres have some semi-supervised living accommodation, but patients in these can see the doctor only if they specifically ask to-a decision that is simply beyond the capacity of many chronic schizophrenics. The conditions in most such centres, my informants tell me, are often squalid, with much confusion and violence. The ten to twelve-bedded wards in the local public general hospitals have usually had to be grafted into very old and crowded buildings. In order to be tolerated by the general medical and surgical treatment teams in the adjacent wards, in many hospitals the psychiatric patients have to be kept under heavy doses of neuroleptics, and in some hospitals, with permanent attendant carabinieri. The dangers of this procedure in Italy have been documented by Bollini et al. ${ }^{5}$ The small clinics and hospitals associated with the universities have generally kept out of the system, except in places such as Padua, a centre where extreme left-wing factions have much influence. Today many university clinics find themselves quite unable to cope with the demand for beds and services made by desperate families and harassed psychiatrists in the public sector.

Since there are now no public hospital facilities in Italy for patients to go to after the statutory forty-eight hours (renewable for up to fourteen days), how does the system cope with the large number of psychiatric patients who need, under any rational system of psychiatry, more than fourteen days' treatment in hospital? Mosher claims that by 1981 there had been 'little evidence' of dumping and 'no appreciable increase' in admissions to private psychiatric hospitals. Unfortunately, no statistics on these points are available anywhere in Italy, but my informants in 1984 paint a very different picture. There has in fact been a great increase in the number of patients in private hospitals or nursing homes, which are available almost exclusively for those who can afford to pay from their own resources. The level of insurance coverage does not nearly meet the demand. Those who cannot afford to pay must join the 'street people', or rotate in and out of jail; a large proportion are kept by their families. This latter experience has led to the formation of four organized groups in Italy of relatives who are campaigning vigorously for a change in the law. A large number of patients in the South Tyrol cross the border and seek treatment in the hospitals associated with the University of Innsbruck. A little known fact about Basaglia's early pioneering efforts in Gorizia and Trieste is that he attained his goals in closing the local public hospitals partly by refusing admission to severely ill patients deemed unsuitable for admission', who were subsequently admitted to hospitals in Treviso, Verona and Milan. Also, Basaglia did not consider alcoholism to be a psychiatric illness, nor did he recognize psychogeriatrics as part of psychiatry, so no provision was 
made for hospital care for these categories of patients.

From the beginning, the Basaglia plan has been vigorously supported by the Communist Party-for their own political reasons. It may be noted that the Basaglia form of psychiatry does not in the least resemble the form practised in the Soviet Union and other Communist countries, which adheres firmly to a hospital-based system and an organic aetiology for chronic schizophrenia. On the other hand, the Italian Communist Party is somewhat different from the Russian party. Initially, many of the other Italian political parties supported the new law, but following the uproar from anguished relatives and a large number of psychiatrists, they now are all, except for the Communist Party, attempting to amend the law in various major ways. A law in draft, to establish a new network of Centres for Treatment and Rehabilitation, where patients can stay for up to six months, has widespread popular, political and medical support. However, a major difficulty is posed by the fact that there are few facilities existent to locate these centres; the space freed in the old hospitals by the mass expulsion of the patients has been largely filled by schools, social work facilities, small apartments for patients, or the buildings are simply falling down through lack of maintenance. Moreover, there is little money available to finance these new centres.

An Italian colleague in academic psychiatry estimated that some 60 per cent of Italian psychiatrists today strongly oppose the Basaglia system, some 20 per cent are passionately in favour of it, and some 20 per cent are neutral. These divisions follow closely the political persuasion of the protagonists. However, it must be noted that the Italian Psychiatric Association is strongly influenced by Basaglia's followers. It is not unusual for fanatical followers of a minority cult to infiltrate official bodies in this way.

There are, however, some positive features about the Basaglia plan. The atmosphere in the large hospital in Venice that I visited was very pleasant, with 150 patients living as guests in its various palazzos. The emotional impact was one of warmth, tolerance and almost gaiety. All the patients had no family to go to or did not wish to leave the hospital which had been their home for many years. One could not help being impressed likewise with the dynamic enthusiasm and personal warmth that the young staff psychiatrists bring to their task of social revolution. Unfortunately, all the dedication, enthusiasm and emotional warmth in the world cannot remedy the fact that schizophrenia is a catastrophic illness and not a way of life or a psychosocial reaction to 'authoritarianism, hierarchy, and inflexibility'. Many schizophrenics must be treated in hospital for more than forty-eight hours (renewable to fourteen days). Many schizophrenics never recover to the extent that they can ever live, even in semi-supervised apartments, and are in need of the long-term care that the much maligned word 'asylum' used to entail. But there is surely no earthly reason why this care, enthusiasm and warmth cannot be lavished on patients in a medium-stay hospital as much as in a fourteen-day stay hospital. Certainly no one would wish to return to the bad old days when psychiatric hospitals were almost indistinguishable from prisons. But the chronic mentally ill deserve better (and not only in Italy) than their present fate decreed by budget cuts grafted onto the lingering effects of the outworn sociological dogmas of the 1960s. It could be argued that the mentally ill were treated better, in some respects, in the United States and England of the 1870s after the reforms led by the Tukes and by Dorthea Dix, than they are treated today.

The conclusions drawn by Jones and Poletti ${ }^{3}$ following their visit to Italy are very similar to those I present in this paper. In fact, the picture they painted was even grimmer, since they visited the south of Italy where conditions are even more appalling than in the north. They accuse the British supporters of Psichiatria Democratica of tunnel vision, unfamiliarity with the different culture, inability to sift propaganda from truth in the claims made by Psichiatria Democratica and from the usual English response to a sudden immersion in romantic Italy. Furthermore, Jones and Poletti ${ }^{3}$ state that this romantic fictionalized version of the 'Italian experience' put about by its supporters in England is being used as a lever for change 'with the implication that mental hospitals can be abolished in England without extensive and expensive substitutes, that patients can be reabsorbed into the community without pain or effort. The real lesson is that this has been tried in Italy, and it has failed ... This is a conclusion that I strongly support as a result of my own investigations. One is reminded of the remarkable fact that people as intelligent as Sydney and Beatrice Webb were deluded into claiming in their book, Soviet Communism: A New Civilization, that the political system of the Soviet Union represents a great advance for good in the human condition. It will be recalled that their eccentric conclusions were based on an examination of the Soviet Constitution as written, which, by this time, as everyone knows, bears not the slightest resemblance to the facts of Soviet political life. Likewise the propaganda put out by supporters of Psichiatria Democratica bears only a tenuous relationship to the facts of how psychiatric patients fare in Italy today.

\section{University of Alabama}

JOHN R. SMYTHIES

Birmingham, Alabama

\section{REFERENCES}

'THIELS, C. (1984) High dose neuroleptics in Italy. British Journal of Psychiatry, 145, 212-213.

2Mosher, L. R. (1982) Italy's revolutionary mental health law: An assessment. American Journal of Psychiatry, 139, 199-203.

3Jones, K. \& Poletr, A. (1985) Understanding the Italian experience. British Journal of Psychiatry, 146, 341-347.

4JoHL, S. S. (1985) Italian psychiatry. Bulletin of the Royal College of Psychiatrists, 9, 73-74.

sBollini, P., andreani, A., Colombo, F., Bellantuono, C. Beretta, P., Arduins, A., Galli. T. \& Tugoni, G. (1984) High dose neuroleptics: Uncontrolled clinical practice confirms controlled clinical trials. British Journal of Psychiatry, 144, 25-27.

\section{The Samaritans branch psychiatrists}

\section{DEAR SIRS}

Recently I have spoken to some other Samaritans branch psychiatrists and we feel that it would be useful to convene a meeting of branch psychiatrists to discuss aspects of the work 